\section{Effect of brefelidin A and monensin on Japanese encephalitis virus maturation and virus release from cells}

\author{
Vaibhavi Jawahar Lad, Ashok Kumar \\ Gupta \\ National Institute of Virology (ICMR), \\ Pune, India
}

\section{Abstract}

Japanese encephalitis virus (JEV) replicates in a variety of cells, the exact intracellular site of virus assembly is somewhat obscure. The aims of this study were to investigate the role Golgi apparatus in JEV maturation by utilizing two Golgi-disrupting agents- brefeldin A (BFA) and monensin (MN) that inhibit virus assembly at specific cellular sites. JEV-infected porcine kidney stable (PS) cells were treated with BFA $(2 \mathrm{ug} / \mathrm{mL})$ or $\mathrm{MN}(10 \mathrm{uM} / \mathrm{mL})$ at different $\mathrm{h}$ post-infection (p. i.) and the virus contents were assayed after $48 \mathrm{~h}$ p. i. The treated cells were further subjected to immuno-fluorescence (IF) using antibodies directed against JEV envelope glycoprotein (gpE) for localization of intracellular viral antigen as well as the antigen expression on the cell surface. Addition of BFA or MN to cells immediately after virus adsorption or at $4 \mathrm{~h}$ and $12 \mathrm{~h}$ postinfection (p. i.), resulted in 4- or 8- fold reduction in infectious virus contents along with inhibition of its transport to the cell surface, indicating an essential role of the Golgi-associated membranes in JEV replication. Interestingly, the antigenicity of the virus, in contrast, remained unaffected as no difference in epitope presentation/ expression was observed in BFA/MN-treated and control (untreated) infected cells even though in the former cells a loss of hemagglutinating (HA) activity was observed. Further, BFA addition at $18 \mathrm{~h}$ or $24 \mathrm{~h}$ p. i. showed only a negligible effect on virus suggesting that once the viral-associated membranes are formed, these membranes appear to be stable. In contrast, the inhibition with $\mathrm{MN}$ persisted even after its addition to cells at $18 \mathrm{~h}$ and $24 \mathrm{~h} \mathrm{p}$. i., indicating its sustained effect on JEV. Although BFA inhibits protein transport from endoplasmic reticulum (ER) to the Golgi complex while MN inhibits transport from medial to trans cisternae of the Golgi complex, none of the two agents however affected the gpE synthesis and folding essentially required for the epitope presentation/expression within the cells. As flaviviruses are known to encode three glycoproteins (gps) within their genomes i. e., prM, $\mathrm{E}$, and NS, it will be worthwhile in future to determine whether vesicular transport occurs within or between the virus-induced membranes and how the individual JEV-encoded proteins are transported to discrete compartments further remain to be seen.

\section{Introduction}

Japanese encephalitis virus (JEV) is one of the most dreaded mosquito-borne flaviviruses (the genus- Flavivirus and familyFlaviviridae) that causes frequent epidemics of acute encephalitis throughout South-east Asia and Western Pacific regions. ${ }^{1-3}$ The disease has also emerged in the non-Asian region such as Northern Australia as reported in recent past. ${ }^{4}$ The virus replicates in a variety of cells- of mammalian, avian and mosquito origin and is probably released by a budding process. ${ }^{5}$ Using Kunjin virus (KUNV) as a model to study the events of flavivirus replication, it appears that virus particles are closely associated with the KUN factories in which compartmentalization within the induced membranes occurs to ensure efficient replication; the exact intracellular site of flavivirus assembly somewhat remains obscure. ${ }^{6,7}$ Ultrastructural studies of flavivirus-infected cells have consistently revealed apparent mature virions within distended endoplasmic reticulum (ER), large cytoplasmic vesicles, and vacuoles. ${ }^{8}$ In addition, occasional sections have shown individual particles within Golgi cisternae, indicating that flavivirus maturation might be proceeding through the Golgi apparatus. ${ }^{9,10}$ However, this process may not be a generalized phenomenon for all the flaviviruses as the viral E protein which is the binding site of neutralizing antibodies, is glycosylated in some flaviviruses while in others it is unglycosylated. ${ }^{6} 11$ The JEV gpE has one conserved Nglycosylation site at the amino acid 150 from the N-terminus. ${ }^{12-14}$ The glycans associated with the JEV gpE are converted in to complex forms prior to the virus release from cells and in the presence of tunicamycin (Tm), a potent $\mathrm{N}$-glycosylation inhibitor, the secretion of $\mathrm{gpE}$ is significantly impaired while that of NS 1 and NS 1' is completely abolished. ${ }^{15}$ In contrast, Brefeldin A (BFA) is a fungal metabolite that disrupts intracellular membrane traffic at the ER-Golgi junction while monensin (MN) is a well-characterized metabolite of Streptomyces cinnamonensis that binds $\mathrm{Na}^{+}, \mathrm{K}^{+}$and proteins, and inhibits trans-Golgi function by preventing the protein transport from medial to trans-cisternae of Golgi compartment. ${ }^{16,17}$ Both BFA and MN have effectively been used to inhibit the transport and secretion of a number of cellular and viral proteins in a variety of cells. ${ }^{6,7}$ Our preliminary studies with JEV
Correspondence: Ashok Kumar Gupta, Centre for Biotechnology,Pravara Institute of Medical Sciences, Loni- 413736, India.

Tel. +91.9960071291; Fax: +91.2422 .273413 .

E-mail: drashok.gpt@gmail.com

Key words: Japanese encephalitis virus, replication, brefeldin A, monensin, PS cells.

Acknowledgments: the authors would like to thank the Director of the National Institute of Virology, Pune for the facilities and Mrs. S.A. Sarthi for providing monoclonal antibodies.

Contributions: VJL, microbiology project; AKG, research supervision.

Conflict of interest: the authors report no conflicts of interest.

Received for publication: 25 May 2011

Revision received: 14 July 2011.

Accepted for publication: 29 July 2011.

This work is licensed under a Creative Commons Attribution NonCommercial 3.0 License (CC BYNC 3.0).

(C) Copyright V.J. Lad and A.K. Gupta, 2011

Licensee PAGEPress, Italy

Microbiology Research 2011; 2:e9

doi:10.4081/mr.2011.e9

revealed that treatment of PS cells with BFA added immediately after virus adsorption resulted in inhibition of virus maturation and its transport to the cell surface. ${ }^{18}$ The present study was undertaken utilizing both BFA and MN in order to attempt inhibition of virus assembly at specific cellular sites in PS cells and assessing their effect by determining the virus yield along with localization of intracellular viral antigen as well as the antigen expression on the cell surface using antibodies directed against JEV gpE by immuno-fluorescence (IF).

\section{Materials and Methods}

\section{Virus and cells}

The details of JEV and PS cells used during the study are given elsewhere. ${ }^{18,19}$ In brief, JEV strain 733913 , originally isolated from a fatal case of JE was adapted to PS cells grown in Earle's based minimum essential medium (MEM, Gibco, invitrogen Corp., Carlsbad, CA, USA) supplemented with $10 \%$ of goat serum. The virus passaging in PS cells was carried out in MEM supplemented with $2 \%$ goat serum and the virus stocks were stored at $-70^{\circ} \mathrm{C}$.

Monoclonal and polyclonal antibodies

Monoclonal antibodies (MAbs) were raised 
earlier in our laboratory against JEV gpE and were grouped as HAI- positive, HAI- negative virus- specific, HAI- positive, HAI- negative flavivirus cross-reactive and HAI- negative autoreactive MAbs depending on their reactivity with JEV, West Nile and Dengue viruses. ${ }^{20,21}$ The respective hybrid cells were maintained in the Dulbecco's based MEM supplemented with $10 \%$ fetal calf serum (both from Gibco) and were inoculated intra-peritoneally into pristane-primed BALB/c mice, ascitic fluids (AFs) were collected by standard methods. Control AF was also obtained by inoculating SP2/0 cells or a MAb prepared against Chikungunya virus (CHIKV-an Alphavirus, the familyTogaviridiae) which did not cross-react with JEV, served as negative control. ${ }^{22}$ Polyclonal antibodies (PAbs) to JEV and a control AF were raised in Swiss mice by immunization with JEV or control (uninfected) antigen respectively, followed by ascites production employing Ehrlich's tumor cells by standard procedures.

\section{Japanese encephalitis virus infec- tion and Brefeldin A/Monensin treatment of PS cells}

Confluent PS monolayers grown in 2.5' petri dishes and on coverslips in Leighton tubes were infected with JEV as mentioned elsewhere. ${ }^{18,19}$ After virus adsorption at $37^{\circ} \mathrm{C}$ for $1 \mathrm{hr}$, the virus inoculum was removed and MEM supplemented with $2 \%$ goat serum and BFA (2 ug/ mL) or MN (10 uM/ mL) (both from Sigma-Aldrich Corp., St. Louis, MO, USA) was added. The cells grown on medium but without BFA or MN served as controls. The cells were incubated for various times at $37^{\circ} \mathrm{C}$ prior to assaying the infectious virus and for antigenicity by IF.

\section{Immunofluorescence studies}

Coverslips with virus-infected cell monolayers either treated or untreated with BFA MN were fixed at $24 \mathrm{~h}$ and $48 \mathrm{~h}$ post-infection (p. i.) in chilled acetone $\left(-20^{\circ} \mathrm{C}\right)$ for $20 \mathrm{~min}$, probed with different MAbs or JEV antiserum diluted 1:100 and stained with a goat antimouse immunoglobulin fluorescein isothiocyanate (GAM Ig-FITC) conjugate (Sigma). ${ }^{23}$ The cells were also probed for surface immunofluorescence (IF) at $36 \mathrm{~h}$ p.i. by treating the unfixed cells with different MAbs or JEV antiserum diluted 1:100 in MEM containing sodium azide as mentioned earlier. ${ }^{24}$ Subsequently, the antibody-treated cells were fixed in chilled acetone $\left(-20^{\circ} \mathrm{C}\right)$ for $20 \mathrm{~min}$ and stained with a GAM Ig-FITC conjugate as above.

\section{Assaying of infectious virus}

Tissue culture supernates (TCFs) and cell lysates collected from the treated cells and the untreated (control) cells at $48 \mathrm{~h}$ p. i. were assayed for the infectious virus in vitro (by plaque titration in PS cells using 24-well plate) as described earlier. ${ }^{18,19}$ The results were expressed as $\log$ PFU/mL.

\section{Hemagglutination assay}

The effect of BFA and MN on Hemagglutination (HA) activity of the virus was studied by assaying HA titres of the TCFs and cell lysates collected from both treated and untreated virus-infected cells employing goose erythrocytes as described earlier. ${ }^{19}$

\section{Treatment of Japanese encephalitis virus -infected PS cells with Brefeldin/Monensin for different times}

BFA and MN were similarly added to the infected cells at various times viz. $4,12,18$ and $24 \mathrm{~h}$ p. i. rather than immediately after virus adsorption. In some experiments, BFA and MN were added immediately after virus adsorption; these were removed from the treated cells at various times viz. $4,12,18$ and $24 \mathrm{~h} \mathrm{p}$. i. and the cells were incubated further without BFA or MN. TCFs and cell lysates collected from the cells were assayed at $48 \mathrm{~h} \mathrm{p}$. i. for the infectious virus as above.

\section{Results}

Incubation of JEV-infected cells in presence of BFA or MN added immediately after virus adsorption drastically reduced the intracellular and extracellular infectious virus yield at $48 \mathrm{~h}$ p. i. by about 4 -fold and 8 -fold, respectively
(Figure 1). This was further accompanied with undetectable HA activity of the virus with the treated cells (HA titres of 1:48 to 96 with untreated cells yielding 7.5-8.0 logs of the virus as against 1.0-2.0 logs only with the treated cells). Whereas, the intracellular presentation of the epitopes on JEV gpE however, appeared to be unaffected either by the BFA or MN treatment of infected cells which showed characteristic apple- green IF at $24 \mathrm{~h}$ and $48 \mathrm{~h}$ p. i. with the MAbs and PAbs to JEV. In contrast, the MAbs and PAbs failed to produce any IF on the surface of BFA MN treated cells at 36 h. p. i., indicating a defective virus transport and/or virus assembly as reported earlier with BFA. ${ }^{18}$ No IF with SP2/0 or CHIKV MAb and control AF was seen with treated or untreated infected cells by either method.

Further, BFA or MN addition to the cells even at $4 \mathrm{~h}$ or $12 \mathrm{~h}$ p. i. resulted in a drastically reduced infectious virus yield (Figure 2). In contrast, the inhibitory effect of BFA was negligible at $18 \mathrm{~h}$ or $24 \mathrm{~h}$ p. i. as only a marginal decrease in virus yield was recorded in comparison to the MN. Even removal of MN (at 4, 12,18 and $24 \mathrm{~h} \mathrm{p}$. i.) after its addition to the cells immediately after virus adsorption produced only a little change, indicating a sustained effect produced by MN in comparison to BFA (Figure 3). As the characteristic virusinduced membranes are not clearly formed until about the end of the latent period i. e. about $12 \mathrm{~h}-15 \mathrm{~h}$, the present results with BFA therefore, indicate an essential involvement of some of the Golgi apparatus-associated membranes in JEV replication. ${ }^{6,7}$ Once these viralassociated membranes are formed as observed on BFA addition just after the end of latent period i. e., $18 \mathrm{~h}$ and later on, the previously induced membranes appear to be stable/ resistant. In contrast, the inhibition with MN
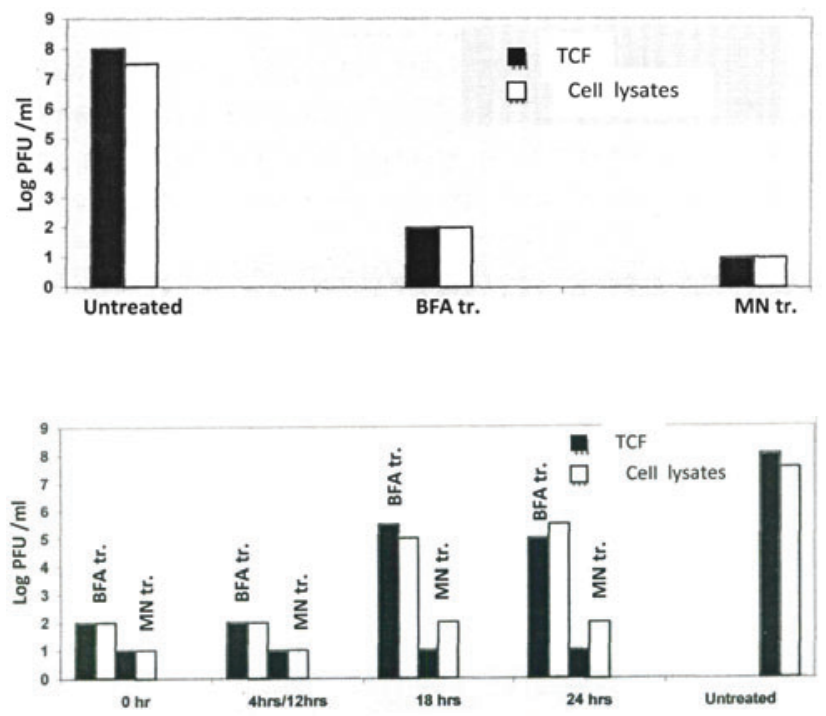

Figure 1. Virus infectivity titres in TCFs and cell lysates collected at $48 \mathrm{~h}$ p. i. from BFA or MN - treated and untreated infected PS cells. BFA tr. $=$ BFA treated, $\mathrm{MN}$ tr. $=\mathrm{MN}$ treated. BFA / MN at different time hours p.i. Effect of BFA $(2 \mu \mathrm{g} / \mathrm{mL})$ or MN (10 $\mu M)$ added at different time interval on JEV replication in PS cells. BFA tr. $=$ BFA treated, $\mathrm{MN}$ tr. $=\mathrm{MN}$ treated. 
persisted even after the end of latent period, suggesting its sustained effect on JEV.

\section{Discussion}

Flaviviruses contain an electron dense icosahedral nucleocapsid core which is surrounded by a lipid bilayer containing envelope protein and the genomic RNA serves itself as mRNA that gets translated into a long polyprotein encoding three structural proteins (C, M and E) and seven NS proteins. ${ }^{25}$ The polyprotein is processed, co- and post-translationally into individual proteins by the host and viral proteases. ${ }^{25-27}$ The M protein represents C' terminal cleavage product of the precursor protein i. e., prM undergoes delayed cleavage that is taking place just prior to or even during virions' release from cells. ${ }^{28-31}$ The cleavage has shown to be catalyzed by the host proteasefurin located specifically in trans cisternae of the Golgi complex..$^{32}$ As the prM and not M protein which is glycosylated and is associated with $\mathrm{E}$ protein in a hetero-dimeric form namely, prM-E. ${ }^{33}$ This interaction between prM and E protein, namely hetero-dimeric $p r M$ is necessary to protect E protein from irreversible conformational changes during maturation in the acidic vesicles of the exocytic pathway. ${ }^{29,31}$ Also the prM facilitates correct folding of E protein or alternatively masks a retention signal within it, thus allowing its exit from the ER. ${ }^{34-37}$

\section{Conclusions}

In the present study utilizing the metabolic inhibitors that inhibit protein and/or membrane traffic throughout the cell, the secretion of JEV particles late in infection was significantly affected/ impaired in the BFA or MN presence along with undetectable antigen on the cell surface. Thus, it seems that though the virus yield is affected, BFA or MN treatment does not affect JEV gpE and its folding essentially required for the epitope expression/presentation as the inhibition of terminal $\mathrm{N}$-glycosylation, i. e. no addition of sialic acid due to non-availablity of sialyl transferasee and its location in trans-Golgi-network. ${ }^{38,39}$ As BFA treatment of cells restricts anterograde protein transport between the ER and Golgi apparatus leading to recycling of viral proteins between the ER and IC, the present results therefore suggest the movement of cellular or viral proteins from the ER to the Golgi apparatus that might essentially be required for membrane induction, rather than just accumulation of viral proteins within the ER and IC. ${ }^{40}$ In contrast, the movement of virus particles within

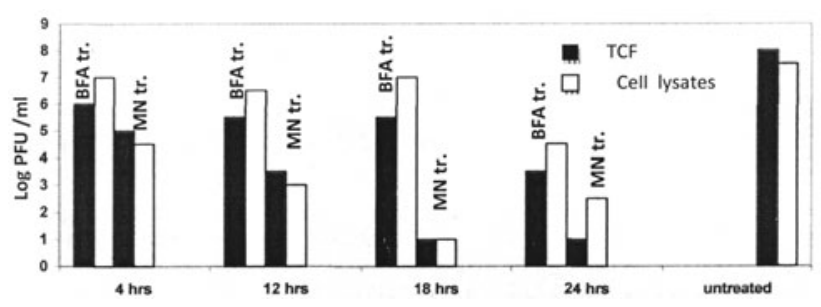

Figure 3. Removal of BFA / MN at different time hours p.i. Effect of BFA $(2 \mu \mathrm{g} / \mathrm{mL})$ or MN (10 $\mu \mathrm{M})$ added at different time interval on JEV replication in PS cells. BFA tr. $=$ BFA treated, $\mathrm{MN}$ tr. $=\mathrm{MN}$ treated.

the medial Golgi compartment during the MN treatment may not be arrested but subsequent furin cleavage of prM was either not occurring or was very inefficient, thus not allowing the conformational change in the $\mathrm{E}$ protein (of immature particles containing prM) that is essentially required for un-coating and fusion with endosomal membranes after infection. ${ }^{15}$ In addition to the obvious inhibition of cleavage of prM, MN also appears in some unknown way to inhibit the cleavage. ${ }^{29}$ Therefore, it will be worthwhile in future to determine whether vesicular transport occurs within or between the virus-induced membranes and how the individual JEV-encoded proteins are transported to discrete compartments further remains to be seen.

\section{References}

1. Monath TP, Heinz FX. Flaviviruses. In: Fields BN, Koipe DM, Howley PM, eds. Field's Fundamental Virology. 3rd Ed. Philadelphia: Lippincott- Raven; 1996. pp. 961-1034.

2. Solomon T, Ni H, Beasley DW, et al. Origin and evolution of Japanese encephalitis virus in Southeast Asia. J Virol 2003; 77:3091-8

3. Vaughn DW, Hoke CH. The epidemiology of Japanese encephalitis: prospects for prevention. Epidemiol Rev 1992;14:197221.

4. Hanna JN, Ritchie SA, Philips DA, et al. Japanese encephalitis in North Queensland, Australia, 1998 Med J Aust 1999;170:533-66.

5. Brinton MA. Replication of flaviviruses. In: Schlesinger S, Schlesinger MJ, eds. The Togaviridae and Flaviviridae. New YorkLondon: Plenum Press; 1986. pp. 327-74.

6. Mackenzie JM, Jones MK, Westaway EG. Markers for trans-Golgi membranes and the intermediate compartment localize to induced membranes with distinct replication functions in flavivirus-infected cells. J Virol 1999;73:9555-67.

7. Mackenzie JM, Westaway EG. Assembly and maturation of the flavivirus Kunjin Virus appear to occur in the rough endo- plasmic reticulum and along the secretory pathway, respectively. J Virol 2001;75: 10787-99.

8. Murphy FA. St. Louis encephalitis. In: Monath TP, ed. Morphology and Morphogenesis. Washington, D.C.: American Public Health Association Inc.; 1980. pp. 65-103.

9. Barth, OM. Ultrastructural aspects of the dengue virus (flavivirus) particle morphogenesis. J Submicrosc Cytol Pathol 1999;31:407-12.

10. Hase T, Summers PL, Eckels KH, Baze WB. Maturation process of Japanese encephalitis virus in cultured mosquito cells in vitro and mouse brain cells in vivo. Arch Virol 1987;96:135-51.

11. Roehring JT. The use of monoclonal antibodies in studies of the structural proteins of togaviruses and flaviviruses. 111. Flaviviruses. In: Schlesinger S, Schlesinger MJ. The Togaviridae and Flaviviridae. New York-London: Plenum Press; 1986. pp. 265-72.

12. McAda PL, Mason PW, Schmaljohn CS, et al. Partial nucleotide sequence of the Japanese encephalitis virus geneome. Virology 1987;158:348-60.

13. Sumiyoshi H, Mori C, Fuke I, et al. Complete nucleotide sequence of the Japanese encephalitis virus geneome RNA. Virology 1987;161:497-510.

14. Nityaphan S, Grant JA, Trent DW. Nucleotide sequence of the virulent SA-14 strain of Japanese encephalitis virus and its attenuated vaccine derivative, SA-1414-2. Virology 1990;177:541-52.

15. Mason PW. Maturation of Japanese encephalitis virus glycoproteins produced by infected mammalian and mosquito cells. Virology 1989;169:354-64.

16. Fujiwara T, Oda k, Yokoto S, et al. Brefledin A causes disassembly of the Golgi complex and accumulation of secretory proteins in the endoplasmic reticulum. J Biol Chem 1988;263:18545-52.

17. Misumi Y, Misumi Y, Miki K, Takatsuki A, Tamura G, Ikehara Y. Novel blokade by brefeldin A of intracellular transport of secretory proteins in cultured rat hepatocytes. J Biol Chem 1986;261:11398-403.

18. Lad VJ, Gupta AK. Inhibition of Japanese 
encephalitis virus maturation and transport in PS cells to cell surface by brefeldin A. Acta Virol 2002;46:187-90.

19. Lad VJ, Shende VR, Gupta AK, et al. Effect of tunicamycin on expression of epitopes on Japanese encephalitis virus glycoprotein $\mathrm{E}$ in porcine kidney cells. ActaVirol 2000;44:359-64.

20. Cecilia D, Gadkari D, Kedarnath N, Ghosh SN. Epitope mapping of Japanese encephalitis virus envelope protein using monoclonal antibodies against an Indian strain. J Gen Virol 1988;692741-7.

21. Kedarnath N, Dayaraj C, Sathe PS, et al. Monoclonal antibodies against Japanese encephalitis virus. Indian J Med Res 1986;84:125-33.

22. Lad VJ, Gupta AK, Ghosh SN, Banerjee K. Immunofluorescent studies on the replication of some arboviruses in nucleated and enucleated cells. Acta Virol 1993;37:79-82.

23. Gupta AK, Gore MM, Lad VJ, Ghosh SN. Nuclear immunofluorescence in porcine kidney cells infected with Japanese encephalitis virus. ActaVirol 1991;35:2826.

24. Gupta AK, Lad VJ, Ghosh SN. Detection of viral antigens on the surface of the cells infected with Japanese encephalitis virus by modified immuno-fluorescent technique. Acta Virol 1993;37:93-6.

25. Rice CM. Flaviviridae: the viruses and their replication. In: Fields BN, Knipe DN, Howley PM, et al., eds. Virology. 3rd ed. Philadelphia, PA: Lippincott-Raven; 1996. pp. 931-59.

26. Westaway EG, Mackenzie JM, Kenney MT, Jones MK, Khromykh AA. Ultrastructure of
Kunjin virus-infected cells: colocalization of NS1 and NS3 with double-stranded RNA and of NS2B with NS3 in virus-induced membrane structures. J. Virol.1987; 71:6650-61.

27. Chambers TJ, Grakoui A, Rice CM. Processing of the yellow fever virus nonstructural polyprotein: a catalytically active NS3 proteinase domain and NS2B are required for cleavages at dibasic sites. J. Virol. 1991; 65: 6042-50.

28. Shapiro D, Brandt WE, Cardiff RD, Russell PK. The proteins of Japanese encephalitis virus. Virology 1971; 44:108-24.

29. Randolph VB, Winkler G, Stollar V. Acidotropic amines inhibit proteolytic processing of flavivirus prM protein. Virology 1990;174:450-8.

30. Guirakhoo F, Bolin RA, Roehrig JT. The Murray Valley encephalitis virus prM protein confers acid resistance to virus particles and alters the expression of epitopes within the R2 domain of $\mathrm{E}$ glycoprotein. Virology 1992;191:921-31.

31. Guirakhoo F, Heinz FX, Mandl CW, et al. Fusion activity of flaviviruses: comparison of mature and immature (prM containing) tick-borne encephalitis virions. J Gen Virol 1992;72:1323-9.

32. Stadler K, Allison SL, Schalich J, Heinz FX. Proteolytic activation of tick-borne encephalitis virus by furin. J Virol 1997; 71:8475-81.

33. Wengler G, Castle E, Leider U, et al. Sequence analysis of the memebrane protein V3 of the flavivirus West Nile and of its gene. Virology 1985;147;264-74.

34. Konishi E, Mason PW. Proper maturation of the Japanese encephalitis virus envelope glycoprotein requires co-synthesis with the pre-membrane protein. J Virol 1993;67:1672-75.

35. Heinz FX, Stiasny K, Puschner-Auer G, et al. Structural changes and functional control of the tick-borne encephalitis virus glycoprotein $\mathrm{E}$ by the heterodimeric association with protein prM. Virology 1994 198:109-17.

36. Allison SL, Schalich J, Stiasny K, et al. Oligomeric rearrangement of tick-borne encephalitis virus envelope proteins induced by an acidic pH. J Virol 1995;69:695-700.

37. Schalich J, Allison SL, Stiasny K, et al. Recombinant subviral particles from tickborne encephalitis virus are fusogenic and provide a model system for studying flavivirus envelope glycoprotein functions. J Virol 1996;70:4549-57.

38. Chege NW, Pfeffer SR. Compartmentation of the Golgi complex, brefeledin A distinguishes trans Golgi cisternae from trans Golgi cisternae from the trans-Golgi network. J Cell Biol 1990;111:893-900.

39. Locker JK, Griffiths G, Horzinek MC, Rother PJ. 0-glycosylation of the Cornavirus M protein. Differential localization of sialyltransferases in $\mathrm{N}$ - and $\mathrm{O}$ linked glycosylation. J Biol Chem 1992; 267:14094-101.

40. Lippincott-Schwartz J, Donaldson JG, Schweizer A, et al. Microtubule-dependent retrograde transport of proteins into the ER in the presence of brefeldin A suggests an ER recycling pathway. Cell 1990;60:82136 . 